\begin{tabular}{c} 
Volume and Issues Obtainable at Center for Sustainability Research and Consultancy \\
Responsible Education, Learning and Teaching in Emerging Economies \\
ISSN: 2708-4310 (E): 2708-4183 \\
Volume 1: No. 2, December 2019 \\
CSRᄃ \\
Journal homepage: www.publishing.globalcsrc.org/relate \\
\hline
\end{tabular}

\title{
Sense of Civic Responsibility among University Students
}

\section{Tilagavati Subramaniam}

${ }^{1}$ Lecturer, Faculty of Social Sciences, Quest International University, Perak, Malaysia: tilagavati.subramaniam@qiup.edu.my

\begin{tabular}{l}
\multicolumn{1}{c}{ ARTICLE DETAILS } \\
\hline History \\
Revised format: November 2019 \\
Available Online: December 2019 \\
Keywords \\
Sense Of Civic Responsibility, \\
University Student, \\
Curriculum, Extra-Curriculum, \\
Campus Climate Perception
\end{tabular}

\section{JEL Classification:} M14, M19, I23

\begin{abstract}
The purpose of this study is to examine the level of sense of civic responsibility among the university students and to identify specific factors that contribute to a sense of civic responsibility. A total of 1213 final year undergraduates' students were recruited from five public universities. Since Malaysian public universities are heterogeneous in terms of student racial composition, stratified sampling was used to ensure the representativeness of the sample. A cross - sectional survey using a self- administered questionnaire was employed. Statistical Packages for Social Sciences (SPSS) version 22.0 was used in order to analyse the quantitative data obtained in this study. The demographic details and the level of sense of civic responsibility were analysed using descriptive statistics in order to obtain both the frequency and percentage for the data. Meanwhile, multiple regressions were used to determine the most influential factor that predicts a sense of civic responsibility among the final year undergraduate students. The results showed that respondents across the five institutions demonstrated a high level of sense of civic responsibility. Campus climate perception is the main contributor that caused the respondents to have a sense of civic responsibility. With regard to this, an institution of higher education can develop more effective strategies by stressing this factor. Student's campus experiences have the potential to help students acquire the necessary knowledge, skill, values and motivation to take action in their communities as a thoughtful, engaged and socially responsible citizen.
\end{abstract}

(C) 2019 The authors, under a Creative Commons AttributionNonCommercial 4.0

Corresponding author's email address: tilagavati.subramaniam @ qiup.edu.my

Recommended citation: Subramaniam, T., (2019). Sense of Civic Responsibility Among University Students. Responsible Education, Learning and Teaching in Emerging Economies, 1(2), 57-65

DOI: $10.26710 /$ relate.v1i2.1124

\section{Introduction}

Youth is a demanding stage in life. Youth are one nation's great asset and are expected to continuously lead the country to future success. The United Nations defines youth as an individual in the age range of 15-24 years old, while Commonwealth defines youth as anyone between 15-29 years of age. However, current Malaysia National Youth Development Policy (NYDP) defines youth as an individual in the age range from 15 to 40 years old.The Minister of Youths and Sports (Malaysia), Syed Saddiq Syed Abdul Rahman implemented the new Youth Societies and Youth Development Act in 2019 with an amendment to the definition of youth to anyone between the age of 15 to 30 years as the essence of the changes and improvements, in line with the current needs of the youth. The youth population constitutes $40 \%$ of the 
country's total population. Hence, through education, our youths can develop their assets, competencies, skills, and responsibilities as good citizen that are vital for nation building.

The responsibility of higher education is to developing responsible citizens and encouraging engagement in the community. Consequently, the relationship between the community and universities is developed. Numerous studies have focused on youth and education, but most tend to study on different outcome such as involvement in political (Parker \& Trolian, 2015), cognitive and academic development (Roksa, J., Kilgo, C. A., Trolian, T. L., Pascarella, E. T., Blaich, C., \& Wise, K. S.,2017 ), psychological wellbeing (Flett, G., Khan, A., \& Su, C.,2019), civic engagement (Rice, L. L., \& Moffett, K. W.,2019). ), volunteerism (Wee, Mohamed, Aminudin, \& Saidin, 2018) and moral development or social agency (Parker, Barnhardt, Pascarella, \& McCowin, 2016). Thus, this study was conducted to probe into the aspects of youth development strengths specifically, sense of civic responsibility.

Sense of civic responsibility in this study refers to a personal belief and feeling that the individual has about their responsibility and duty to society. Therefore, if a person actively takes action to address community issues and problems, such as attending a community meeting, volunteering, raising money for charity are declared as good citizen of society. Sense of civic responsibility could also be perceived as a personal investment in the wellbeing of others and society as a whole. In other words, citizen who has attained a sense of civic responsibility would be more responsive and supportive of developmental efforts at all level (i.e., social and political). Sense of civic responsibility is well recognised as an important developmental towards becoming a productive citizen in the future. Productive citizen is the outcome of youths who successfully embraced sense civic of responsibility and feel belong to the community in which they live.

The changes in social economic and technology patterns of society have produced shifting in younger citizen's mentality, which are less inclined to feel a sense of duty to participate civically in conventional ways, while displaying a greater inclination to embrace issues connected to lifestyle values, ranging from moral concerns to environmental quality (Ahrari, Othman, Hassan, Samah, \& D'Silva, 2014). Education is a tool by which to help students learn about civic society. Higher education plays a major part in encouraging student participation in public life. Past studies found that higher education not only produces student's with the positive educational outcome but also develop student's with positive selfconcept, problem-solving skills, growth in leadership and cultural awareness, as well as a high level of civic outcome.

In Malaysia, higher education is entrusted to facilitate the development of a sense of civic responsibility among students. In fact, the goal of higher education is not only to prepare students for productive careers, but also to shape a citizenry that can promote the public good. The continuous demand by the Minister of Education in Malaysia to universities and colleges to produce highly qualified graduates, who can serve to the society, has prompted the institution of higher learning to consider the enhancement of the sense of civic responsibility through curricular and co-curricular engagement. Developing a sense of civic responsibility among the students allows the higher education to fulfill their basic mission, which is the preparation of good citizenry upon graduation.

Various factors are associated with youth embracing the value of the sense of civic responsibility, especially in the institutions of higher education. Past studies found that university and colleges' experiences including curriculum and co-curriculum diversity (Garcia \& Cuellar,2018), peer interaction (Taman \& Krauss,2014) and campus climate (Joshua et al., 2016; Bowman et al., 2015; \& Kim et al., 2014) facilitates students' better civic outcomes, moral development and social responsibility. Hurtado, Milem, Clayton-Pedersen and Allen (1998) have contributed a framework focusing on campus engagement for diversity functions. This framework describes two overarching facets of the campus engagement: external and internal contexts. External context epitomizes environmental influences associated with the campus diversity climate and government policy and programs. The internal context 
comprises institutional element such as structural diversity, historical legacy and psychological. The present study underscores two of these dimensions' curriculum and co-curriculum diversity and perception of the campus climate. These elements of the framework appropriately inform the understanding about in-class experiences and perception of campus climate to promote a sense of civic responsibility.

Curriculum and co-curriculum diversity are defined as the extent of engagement in diversity with respect to ideas and people through structured or programmed on campus and off-campus activities. The curriculum involves structured initiatives in the form of academic courses such as students have taken Ethnic Relation course, Civilization and Islamic Civilization course, gender issues course, and foreign language course, participated in a mobility program and attended a leadership workshop. While cocurriculum activities describe as joining an associations or clubs, participating in community projects. This form of engagement is considered formal because of the institutional level of coordination required to implement these activities.

Meanwhile, perception of campus climate refers to student's general view of educational experiences and interethnic relations in the campus. Perception of campus climate is a combination of the norms, behaviours, attitudes, structures and external influences that shape the student experiences and increasing the pervasiveness and effectiveness of student development for a sense of civic responsibility.

In short, to successfully inculcate the value of a sense of civic responsibility among the youth, it is deemed necessary to investigate on the interplay between the higher education experiences of the youth, such as curriculum and co-curriculum diversity and campus climate diversity. The findings of this study may provide significant implications that could be taken into account by relevant parties such as educational institutions and the Ministry of Education.

\section{Objectives of the study}

To date, little is known on the extent of sense of civic responsibility among the university students in Malaysia, including its contributing factors. Therefore, it is of interest to the present study to determine the level of sense of civic responsibility among the university students and to identify specific factors that contribute to a sense of civic responsibility such as curriculum, extra-curriculum and campus climate perception. This study contributes to the field of education by disaggregating factors encouraging student's involvement in social and community affairs. The results of this study reinforce of Tamam (2016) study, who asserted that developing a more informed, deliberative and active citizenry requires adopting a holistic strategy that will make a lasting difference in society. Based on this general objective above, the study addressed two specific objectives:

1) To identify the level of sense of civic responsibility among university students

2) To determine the factors contributing to a sense of civic responsibility among university students

\section{Research Methodology}

\subsection{Sample}

Due to several reasons this study chooses university students as the respondent. First, the formal and informal engagement diversity experience is pertinent among students. Higher education institutions (HEIs) are supposed to provide a diverse learning experience. Second, final year undergraduates students were chosen as the respondents in this study because they have exposed to diverse level of formal and informal activities throughout their study years. A total of 1213 final year undergraduates' students were recruited from five public universities. Since Malaysian public universities are heterogeneous in terms of student racial composition, stratified sampling was used to ensure the representativeness of the sample. A summary of the descriptive characteristics of the respondents is discussed in the results section. 


\subsection{Procedures}

A cross - sectional survey using a self- administered questionnaire was employed. Notices of inviting final year students to participate in the survey were posted at selected residential colleges after getting an approval from the college administrators of the respective universities. Respondents were invited to attend a research meeting session at a preset time and place. The students were brief on the survey and those who agreed to participate were given a questionnaire to fill. Respondent took about 20 to 25 minutes to complete the questionnaire which was written in Bahasa Malaysia (national language). Of the 1213 completed questionnaires were used in the analysis.

\subsection{Measures}

\subsubsection{Demographic Variables}

Respondents' demographic characteristics measured were gender, age, ethnicity, the university attended, studying programme and semester of study. Gender was measured with a single question asking respondents to report whether they are male or female. Age was measured by asking them to write their year of birth. Ethnicity was measured with asking respondents to report whether they are Malay, Chinese, Indian or others. Respondents were asked to indicate which university they are attending. Respondents were asked to report studying programme whether science and technology, humanities and social science or others. The last question asked the respondents to indicate their semester of study.

\subsubsection{Sense of Civic Responsibility}

The students sense of civic responsibility was assessed using a modified version from Doolittle and Faul's civic engagement scale (2013). Sense of civic responsibility was measured through the 9 questions. Respondents were asked to rate how important are the following things to them, on a 7-point scale, ranging from $1=$ not all important to $7=$ extremely important. A sample item from the scale is, "working together to build a better society". The respondents' score was determined by summing up all individual item scores. Higher scores represent a higher sense of civic responsibility.

\subsubsection{Curriculum and Co-Curriculum Diversity}

An index of curriculum and co-curricular diversity engagement was specifically developed for the purpose of the study. The index consisted of 20 questions related to diversity experiences. Respondents were asked to indicate whether they have had the following diversity-related activities during their undergraduates' life, with the response option of yes or no. A sample of item from the scale is, "Attended on-campus talks on social issues", and "Attended cultural awareness program/activities".

\subsubsection{Campus Climate Perception}

Perception on educational experience and interethnic relations on the campus is measured by asking the respondents to indicate their degree of agreement on a five-point scale from strongly disagree (1) to strongly agree (5). A sample item from the scale is, "In this university students get ample opportunities for self- development.

\subsection{Reliability}

Reliability which examines the internal consistency was tested using a Cronbach's alpha coefficient. Reliability analysis was conducted to test the reliability of the instruments and determine whether respondents were interpreting questions as intended. The reliability of the measurement of each variable obtained in this study indicated that all the measurement recorded excellent reliability with coefficient alphas of above 0.6, which is the cut-off point of reliability score recommended by Nunnally (1967). The alpha for a sense of civic responsibility was 0.94 , curriculum and co-curricular diversity 0.82 and campus climate perception diversity 0.76 . Thus, the measures adequately capture the intended study variables.

\subsection{Data Analysis}

Statistical Packages for Social Sciences (SPSS) version 22.0 was used in order to analyse the quantitative data obtained in this study. The demographic details and the level of sense of civic responsibility were 
analysed using descriptive statistics in order to obtain both the frequency and percentage for the data. Meanwhile, multiple regressions were used to determine the most influential factor that predicts a sense of civic responsibility among the final year undergraduate students.

\section{Results}

\subsection{Descriptive Findings}

The descriptive analysis is carried out to find the frequency, percentage, mean and standard deviation of the variables. It helped to analyze the data obtained from the participants.

\subsection{Summary of Respondent Characteristics}

A total of 1213 respondent were participating in the study. There were $52.8 \%$ of female respondents, whereas male respondents accounted for $47.2 \%$ of the total respondents. The range of age was between 20 to 30 years old. Students aged within 20-24 years old made up the largest portion of the respondents which was $90.2 \%$ while there were only $9.8 \%$ of respondents aged between $25-30$ years old. The mean age of the respondents was 23.77 years old and standard deviation was 1.36 years. As for ethnicity, $62.9 \%$ of the respondents were Malay, 20.9\% were Chinese, $11.5 \%$ were Indian and other ethnics only accounted for $4.7 \%$ of the total respondents.

Besides, $61 \%$ of the respondents were pursuing science and technology programme, whereas $30.8 \%$ was taking humanities and social science programme and $8.2 \%$ was pursuing other programmes. With regards to studying university, $23.2 \%$ of respondents were from National University of Malaysia and this was followed by $21.4 \%$ of students from University Science Malaysia, $19.5 \%$ students from University of Malaya, $18.5 \%$ students from University of Technology Malaysia and 17.3\% were from University Putra Malaysia.

\subsection{Level of sense of civic responsibility}

Table 1 provides the summated scale scores of a sense of civic responsibility. To measure the level of sense of civic responsibility, mean score was computed by adding the score of each item and dividing the total score by the number of items. Based on the mean score, the level of sense of civic responsibility was categorised into two groups which were low and high levels of sense of civic responsibility.

\section{Table 1: Level of Sense of Civic Responsibility}

\begin{tabular}{|ccc|}
\hline Level of Sense of civic responsibility & Frequency $(\mathbf{n = 1 2 3 1})$ & Percentage $\mathbf{( \% )}$ \\
\hline Low (1.00-3.99) & 27 & 2.2 \\
High (4.00-7.00) & 1186 & 97.8 \\
\hline
\end{tabular}

The first research objective aim is at determining the level of sense of civic responsibility among the respondents, who were local undergraduate students at five higher education institutions. Descriptive statistics are applied to assess the level (low and high) of a sense of civic responsibility among the respondents.

Table 1 depicts the respondents' level of sense of civic responsibility (low and high) for the full sample. In general, the respondents indicated a high level of sense of civic responsibility. More of the respondents $(97.8 \%)$ showed a high level of sense of civic responsibility $(\mathrm{M}=1.98, \mathrm{SD}=.148)$. Respondents across the five institutions demonstrated a high level of sense of civic responsibility.

\subsection{Relationship between sense of civic responsibility, curriculum and co-curricular diversity and campus climate perception}

Pearson correlation analysis was used to estimate the strength and direction of the association between two variables. The result suggests that there was a significant correlation sense of civic responsibility and curriculum and co-curricular diversity. The positive r-value clarified the positive relationship between two 
variables by explaining students with positive engagement in and out of classroom activities will most probably have a high intention of sense civic responsibility. This finding was consistent with the study conducted by Reason (2013) where he has found that sense of civic responsibility can be influenced by the in and out of classroom activities.

In addition, with regards to the relationship between campus climate perception and sense of civic responsibility, the Pearson correlation (r) was 0.216 and the significant value sig.r (p) was 0.000. This result suggests that there was a significant relationship between these two variables and it also indicated that the higher the level of campus environment concern, the higher the sense of civic responsibility. This result was supported by Ryder et al (2016) as they also reported that there was a significant relationship between campus climate perception and sense of civic responsibility. The result of Pearson correlation analysis, which determined the relationship between sense of civic responsibility, curriculum and cocurricular diversity and campus climate perception amongst students were shown in Table 2.

Table 2: Correlation Analysis for Sense of Civic Responsibility, Curriculum and Co-curricular Diversity and Campus Climate Perception

\begin{tabular}{|lcc|}
\hline Variables & Sense of Civic Responsibility \\
\hline & $\mathbf{r}$ & $\mathbf{p}$ \\
Curriculum and co-curricular diversity & 0.125 & 0.000 \\
Campus climate perception & 0.216 & 0.000 \\
\hline
\end{tabular}

\subsection{Multiple Regression Analysis for Sense of Civic Responsibility}

Multiple regression analysis was used to determine the significant predictors for the respondent's sense of civic responsibility. Anova test for regression analysis shows that there is a significant relationship between both dependent variable and independent variable at the 0.05 significant level. The analysis in Table 3 shows that campus climate perception (Model 1) gives a significant result with $\mathrm{F}=59.532$, $\mathrm{p}<0.05$. As well as the combination of campus climate perception and curriculum and co-curricular diversity (Model 2) which also gives a significant result $(\mathrm{F}=33.716, \mathrm{p}<0.05)$.

Table 3: Analysis of Variance of Variable

\begin{tabular}{lccccc}
\hline \hline Model & Sum of Squares & df & Mean Square & F & Sig.Value \\
\hline 1. & & & & & \\
Regression & 38.970 & 1 & 38.970 & 59.532 & 0.000 \\
Residual & 792.742 & 1211 & .655 & & \\
Total & 831.713 & 1212 & & & \\
\hline 2. & & & & & \\
Regression & 43.904 & 2 & 21.952 & 33.716 & 0.000 \\
Residual & 787.809 & 1210 & .651 & & \\
Total & 813.713 & 1212 & & & \\
\hline \hline
\end{tabular}

Meanwhile multiple regression test shows that (Table 4) campus climate perception significantly contributes to 4.7 percent of variance $(\mathrm{R} 2=0.047)$ towards a sense of civic responsibility. This means that campus climate perception $(\mathrm{B}=0.216, \mathrm{p}<0.05)$ is the main contributor that caused the respondents to have a sense of civic responsibility. However, with the combination of predictor between campus climate perception $(B=0.198, \mathrm{p}<0.05)$ and curriculum and co-curricular diversity $(B=0.079, p<0.006)$ the contribution of variance towards a sense of civic responsibility increased to 5.3 percent. The results about the campus climate perception was the most dominant factors contributing to the sense of civic responsibility was supported by the findings from Pearson correlation analysis in which the r-value of this variable was the highest among the two variables under study. 


\section{Table 4: Multiple Regression Analysis for Sense of Civic Responsibility}

\begin{tabular}{lcccc}
\hline \hline Variables & B & $\boldsymbol{\beta}$ & $\mathbf{t}$ & Sig.Value \\
\hline Curriculum and co-curricular diversity & 0.202 & 0.079 & 2.753 & 0.006 \\
Campus climate perception & 0.223 & 0.198 & 6.893 & 0.000 \\
Constant & 4.487 & & 23.013 & 0.000 \\
\hline
\end{tabular}

Note. $R^{2}=0.053 ;$ Adj. $R^{2}=0.051$

\section{Implications}

This study provides an insight into students for a better understanding of their attitudes and behaviour towards society. From a higher education institutions perspective, it is also vital to understand the determinants that influence s student's sense of civic responsibility in order to develop effective strategies to enhance greater social responsibility. It will also assist in the development of effective community based programs that will subsequently help to promote the sense of civic responsibility among student.

Therefore, universities will be able to explore different programs that would be suitable for positioning community involvement and motivating social responsibility. In addition, major initiative needs to be carried out to convince the students to be responsible for their actions and behaviour towards society. Relevant government agencies will find this study useful by knowing what factors influence Malaysians to care more about community problems so that more campaign can be organized to raise the awareness of a sense of civic responsibility as what other developed countries do.

In detail, firstly, higher education institutions can gain more knowledge and insight into factors that motivate students to involve in society. They are able to design more effective social programs such as volunteering programs, social service and other community programs that are deemed crucial in improving students' sense of civic responsibility. The findings show that those students who perceived themselves as having a high level of sense civic responsibility will be more intended to engage and solve social problems. With regard to this, universities can promote their students by highlighting the benefits of engaging in society and how students can protect and contribute to the well being of the community through a sense of civic responsibility.

Secondly, this study is useful for the policymaker as the role played by the government in community protection is undeniable. Therefore, governments should organize more campaigns and events to raise awareness on the seriousness of social issues. Additionally, since campus climate perception turns out to be the most influential factor that leads to a sense of civic responsibility, these programs should be able to cultivate a positive attitude amongst the students for encouraging more students to enhance their sense of civic responsibility.

Thirdly, this research could be useful for academicians who are interested in conducting studies on the sense of civic responsibility because they might consider including current research's variables in their research framework. Besides, other variables can also be added to future studies to predict what other factors can significantly influence a sense of civic responsibility among the students as the adjusted $\mathrm{R}$ square for the model involving all the two variables was only $5.1 \%$. This means that the remaining $94.9 \%$ might be contributed by other factors that were not included in this study.

\section{Conclusion}

Although the findings of this study had a significant contribution to the previous literature, there are some limitations inherited in it. First, since the data was collected from an undergraduate student in solely five Malaysian public universities, University Putra Malaysia (UPM), University Kebangsaan Malaysia (UKM), University Malaya (UM), University Science Malaysia (USM) and University Technology Malaysia (UTM), finding generalization should be used with caution. This is because the target 
respondents comprised of university students, which not be suitable to represent the Malaysian population as a whole. Another limitation is that the present study was conducted with a specific age group of respondents consisting of undergraduate students. While teenagers or adolescents not educated may have different level of sense of civic responsibility compared with the studied group. This limitation opens up opportunities for the future studies to be replicated and various respondents such as rural adolescent, secondary school students and uneducated youth. Various population contexts would allow researchers to compare different populations to have a better understanding of a sense of civic responsibility.

The growth of the internet and increased use of personal technology devices is fuelling the irresponsible youth. Institutions of higher education must enable the youth to become responsible and discipline members of society. Ultimately it is about equipping them with human resource capacities that can benefit the community and for them to be nation builders. Besides, it was found that the most influential factor that predicts a sense of civic responsibility is campus climate perception. Campus climate perception can aid in reinforcing and encouraging sense of civic responsibility, while minimizing the potential negative effects of dissonance regarding society. Creating experiences and climates that support students as they think about, discern, and act upon their values and beliefs responsibly will help encouragement towards society.

With regard to this, an institution of higher education can develop more effective strategies by stressing this factor. Student's campus experiences have the potential to help students acquire the necessary knowledge, skill, values and motivation to take action in their communities as a thoughtful, engaged and socially responsible citizen.

\section{References}

Ahrari, S., Othman, J., Hassan, S., Samah, B. A., \& D’Silva, J. L. (2015). Youth civic development in the higher education context: Some preliminary results. The Social Sciences,Medwell Journals, 10(3), 285-293.

Bowman, N. A, \& Park, J. J. (2015). Not all diversity interactions are created equal: Crossracial interaction, close interracial friendship, and college student outcomes. Research in Higher Education, 56, 601-621. http://doi.org/10.1007/s11162-015-9365-z

Doolittle,A.,\& Faul, A. C. (2013). Civic Engagement Scale: A Validation Study. SAGE Open. https://doi.org/10.1177/2158244013495542

Flett, G., Khan, A., \& Su, C. (2019). Mattering and Psychological Well-being in College and University Students: Review and Recommendations for Campus-Based Initiatives. International Journal of Mental Health and Addiction. doi:10.1007/s11469-019-00073-6

Garcia, G. A. \& Cuellar, M. (2018). Exploring curricular and co-curricular effects on civic engagement at emerging Hispanic Serving Institutions. Teachers College Record. 120(4),1-36

Hurtado, S., Milem, J. F., Clayton-Pedersen, A. R., \& Allen, W. R. (1998). Enhancing campus climates for racial/ethnic diversity: Educational policy and practice. Review of Higher Education, 21(3), 279-302.

Joshua J. Mitchell, Robert D. Reason, Kevin M. Hemer \& Ashley Finley (2016) Perceptions of Campus Climates for Civic Learning as Predictors of College Students' Mental Health, Journal of College and Character, 17:1, 40-52 http://dx.doi.org/10.1080/2194587X.2015.1125367

Kim, Y. K., Rennick, L. A., \& Franco, M. A. (2014). Latino College Students at Highly Selective Institutions: A Comparison of Their College Experiences and Outcomes to Other Racial/Ethnic Groups. Journal of Hispanic Higher

Nunnally, J. C. (1967). McGraw-Hill series in psychology. Psychometric theory. New York, NY, US: McGraw-Hill.

Parker, E. T., Barnhardt, C. L., Pascarella, E. T., \& McCowin, J. A. (2016). The impact of diversity courses on college students' moral development. Journal of

College Student Development, 57(4), 395-410.

Parker, E. T., \& Trolian, T. L. (2015). Collegiate diversity experiences and students' 
views regarding social and political involvement. Journal of Student

Affairs Research and Practice, 52(4), 387-400.

Reason, R. D. (2013). Infusing Social Responsibility into the Curriculum and Cocurriculum: Campus Examples. New Directions for Higher Education. http://doi.org/10.1002/he.20076

Rice, L. L., \& Moffett, K. W. (2019). Snapchat and civic engagement among college students. Journal of Information Technology \& Politics, 1-18.doi:10.1080/19331681.2019.1574249

Roksa, J., Kilgo, C. A., Trolian, T. L., Pascarella, E. T., Blaich, C., \& Wise, K. S. (2017). Engaging with Diversity: How Positive and Negative Diversity Interactions Influence Students' Cognitive Outcomes. The Journal of Higher Education, 88(3), 297322.doi:10.1080/00221546.2016.1271690

Ryder, A. J., Reason, R. D., Mitchell, J. J., Gillon, K., \& Hemer, K. M. (2016). Climate for learning and students' openness to diversity and challenge: A critical role for faculty. Journal of Diversity in Higher Education, 9(4), 339 352.http://dx.doi.org/10.1037/a0039766

Taman, E. (2016). Are University Students getting enough Interethnic Communication and Diversity Engagement Experiences? Concerns and Considerations. Selangor: UPM Press

Tamam, E. \& Krauss, S. E. (2014). Ethnic-related diversity engagement differences in intercultural sensitivity among Malaysian undergraduate students. International Journal of Adolescence and Youth, 1-14 http://doi.org/10.1080/02673843.2014.881295

The Borneo Post Online. (2015).PM launches new Malaysia Youth Policy.May 16.

Wee, H., Mohamed, N. A., Aminudin, N., \& Saidin, N. (2018). Graduate Attributes, Outcomes of Volunteering and Graduate Employability: The Case of Mice Event Volunteers. International Journal of Academic Research in Business and Social Sciences, 8(15), 